Acta Technologica Agriculturae 1

Nitra, Slovaca Universitas Agriculturae Nitriae, 2015, pp. 6-9

\title{
EXPERIMENTAL DETERMINATION OF SOFT WHEAT FLOUR THERMAL PARAMETERS
}

\author{
Monika BOŽIKOVÁ*, Peter HLAVÁČ, Vlasta VOZÁROVÁ, Luubomír BELÁŇ
}

Slovak University of Agriculture in Nitra, Slovak Republic

\begin{abstract}
This article focuses on temperature relations of selected thermophysical parameters for soft wheat flour. The main aim of experiment was to determine the thermal conductivity, thermal diffusivity and volume specific heat of soft wheat flour in Slovakia marked as Špeciál 00 Extra. Measurements were performed in laboratory settings. Thermal parameters were measured using the thermal analyser Isomet 2104 with two types of probes - a linear probe and plane probe. Measurement by the linear probe is based on a hot wire method, and measurement by the plane probe is based on a simplified plane source method. Both methods are described in the text. Two types of measurement method were used because of the non-homogenous structure of measured material. All thermophysical parameters were measured during the temperature stabilisation in the temperature interval $5-24^{\circ} \mathrm{C}$. Obtained graphical relations had linear increasing progresses with high values of determination coefficients in all cases. Measurement results showed that measurement method has no significant influence on thermophysical parameters values.
\end{abstract}

Keywords: soft wheat flour, temperature, thermal conductivity, thermal diffusivity, relation

Recent results of thermophysical research applied to biobased materials are very important because these materials go through the thermal manipulation during storage and processing to final products. Thermophysical parameters are significant characteristics that can be used for improving of technological processes. If we know the basic thermal parameters, we can determine optimal storage conditions. From changes of thermophysical parameter values during temperature stabilisation, we can predict structural changes of bio-based materials. These facts are very useful in agriculture and food industry for detection of materials quality.

\section{Material and methods}

\section{Characteristics of flour}

The flour that is used in baking comes mainly from wheat, although it can be milled from corn, rice, nuts, legumes, and some fruits and vegetables. Different types of flour are suited to different items. In Slovakia, soft wheat flour, middle cut wheat flour, and whole wheat flour are mostly used. Our research was focused on measuring the selected soft wheat flour thermophysical parameters because this type of flour is usually used for baking. Fine texture is typical for soft wheat flour. One hundred grams of soft wheat flour contain 10.6 $\mathrm{g}$ of proteins, $74.1 \mathrm{~g}$ of saccharine and $1.3 \mathrm{~g}$ of fats. Energy content per $100 \mathrm{~g}$ is $1,474 \mathrm{~kJ}$ (Danster et al., 2008).

The thermophysical parameters of the sample were measured by the thermal analyser Isomet. Measurement by the thermal analyser is based on two types of thermophysical methods - the hot wire method and plane source method. In this case, mainly the plane source method was used for measurements. The hot wire method was used for data reliability comparison. These methods are shortly described in the following text, and detailed description of methods can be found in literature (Božiková and Hlaváč, 2010; Božiková, 2008). The range of the plane and needle probe was chosen according to the thermophysical parameters that are known from literature. During the measurement, the probe is placed into the measured material. There should be very good contact between the measured sample and probe. The thickness of the measured material was $10 \mathrm{~mm}$ for the plane source method. The volume of the sample for the hot wire method was $300 \mathrm{ml}$, and the probe was placed in the centre of the sample with a cylindrical shape. Heat was generated by the probe, and there was analysed the temperature relation in time. The thermophysical parameters - thermal conductivity, thermal diffusivity and volume specific heat were calculated from the timetemperature relation.

The hot wire method is a standard transient dynamic technique based on measuring the temperature rise in a defined distance from a linear heat source (hot wire) embedded in the test material. If the heat source is assumed to have a constant and uniform output along the length of test sample, thermal conductivity can be derived directly from the resulting change in temperature over a known time interval (Davis, 1984). 
The wire probe utilizes the principle of the transient hot wire method. Here, the heating wire as well as the temperature sensor (thermocouple) is encapsulated in the probe that electrically insulates the hot wire and the temperature sensor from the test material (Wechsler, 1992). The hot wire method can be applied in several experimental modifications (Vozár et al., 2010).

The most used method is the simplified hot wire method described in the following text. For an infinitely long metallic wire (length/radius ratio $>>200$ ) heated at time $t>0$ with a constant heat flux per length unit $q$ and immersed in an infinite homogeneous medium (thermal conductivity and diffusivity: $\lambda$ and $a$ ) with uniform initial temperature, the temperature rise $\Delta T(t)$ of the wire is given by Eq. (1) (Carslaw and Jaeger, 1959):

$$
\Delta T(t)=\frac{q}{4 \pi \lambda} \ln \frac{4 F_{0}}{C}
$$

with $C=e^{\gamma}=1.781$, where $\gamma$ is Euler's constant $(\gamma=0.5772)$ and $F_{0}$ the Fourier number defined by Eq. (2):

$$
F_{0}=\frac{a t}{r_{0}^{2}}
$$

Equation (1) is the analytical solution of an ideal thermal conductive model valid for $F_{0}>>1$ and without convective transfers (Healy et al., 1976; Wakeham et al., 1991; Tavman, 1996). From this ideal model and with known $q$ values, thermal conductivity can be calculated by Eq. (3):

$$
\lambda=\frac{q}{4 \pi}\left(\frac{d T}{d(\mathrm{ht})}\right)^{-1}
$$

where:

$d T / d(\ln t)$ - a numerical constant deduced from experimental data for $t$ values which satisfy the condition $F_{0}>>1$

The second method used was the plane dynamic source method. This method is based on using an ideal plane sensor. The plane sensor acts both as a heat source and temperature detector. The plane source method is arranged for a one-dimensional heat flow into a finite sample. The theory considers ideal experimental conditions - an ideal heater (negligible thickness and mass), perfect thermal contact between the plate sensor (PS) and the sample, zero thermal resistance between the sample and the material surrounding the sample, zero heat losses from the lateral surfaces of the sample (Karawacki et al., 1992). If $q$ is the total output of power per unit area dissipated by the heater, then the temperature increase as a function of time is given by Eq. (4) (Beck and Arnold, 2003):

$$
\Delta T(x, t)=2 \frac{q \sqrt{a t}}{\lambda} \operatorname{ierfc}\left(\frac{x}{2 \sqrt{a t}}\right)
$$

where:

a - thermal diffusivity

$\lambda \quad$ - thermal conductivity of the sample

ierfc - the error function (Carslaw and Jeager, 1959)
We consider the plane source sensor, which is placed between two identical samples having the same cross section as the sensor in the plane $x=0$. The temperature increase in the sample as a function of time conforms Eq. (5):

$$
T(0, t)=\frac{q \sqrt{a}}{\lambda \sqrt{\pi}} \sqrt{t}
$$

which corresponds to linear heat flow into an infinite medium (Karawacki and Suleiman, 2001). Thermal conductivity can be determined from the time-temperature relation.

\section{Results and discussion}

The measured sample was stored in a cool box with the internal temperature $4-5{ }^{\circ} \mathrm{C}$. Values of thermal parameters were measured during the temperature stabilisation for the sample of soft wheat flour Špeciál 00 Extra.

The values of thermophysical parameters - thermal conductivity, thermal diffusivity and volume specific heat presented in Figs 1-3 were obtained by thermophysical measurements in the temperature range $5-24{ }^{\circ} \mathrm{C}$. Temperature changes simulated the process during the temperature stabilisation from the minimal storage temperature to the maximal storage temperature. There were analysed the influences of temperature changes on basic thermophysical parameters. The numerical results represented by regression equations in Tables 1-3 showed linear increasing dependencies (Figs 1-3) for thermal conductivity, thermal diffusivity and volume specific heat for the sample of soft wheat flour Špeciál 00 Extra. All presented dependencies have high coefficients of determination in approximate range $0.97-0.98$.

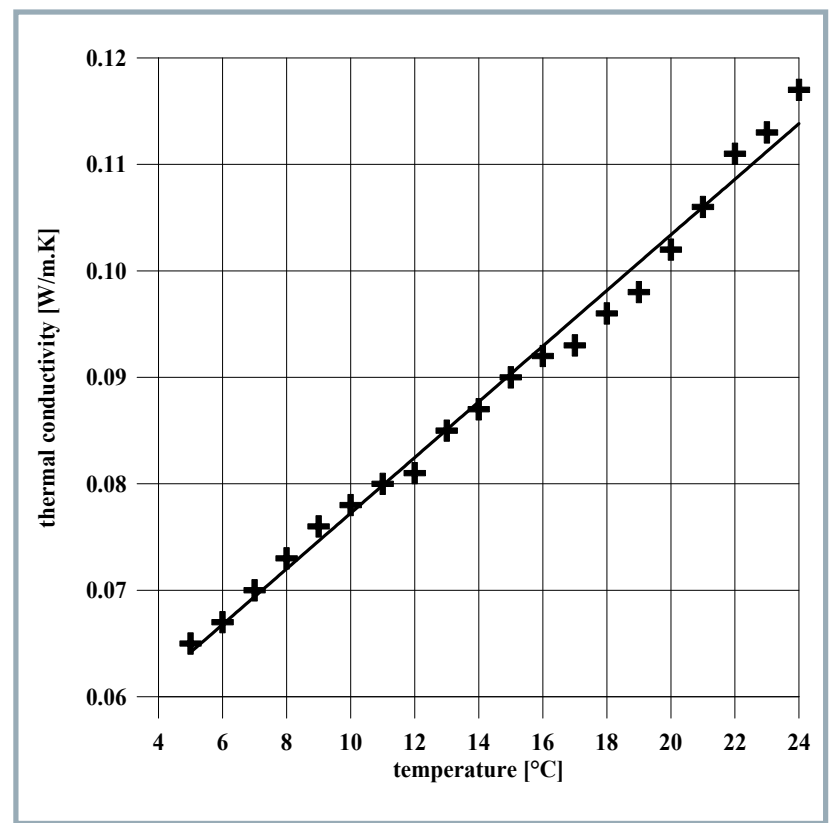

Figure 1 Temperature dependance of thermal conductivity for the soft wheat flour Špeciál 00 Extra in the temperature range $5-24{ }^{\circ} \mathrm{C}$ during the temperature stabilisation 
Table 1 Experimental values of thermal conductivity for the soft wheat flour Špeciál 00 Extra in the temperature range $5-24^{\circ} \mathrm{C}$

\begin{tabular}{|l||c|l||c|}
\hline$t$ in ${ }^{\circ} \mathrm{C}$ & $\lambda$ in W/m.K & $t$ in ${ }^{\circ} \mathrm{C}$ & $\lambda$ in W/m.K \\
\hline \hline $\mathbf{5}$ & 0.065 & $\mathbf{1 5}$ & 0.090 \\
\hline $\mathbf{6}$ & 0.067 & $\mathbf{1 6}$ & 0.092 \\
\hline $\mathbf{7}$ & 0.070 & $\mathbf{1 7}$ & 0.093 \\
\hline $\mathbf{8}$ & 0.073 & $\mathbf{1 8}$ & 0.096 \\
\hline $\mathbf{9}$ & 0.076 & $\mathbf{1 9}$ & 0.098 \\
\hline $\mathbf{1 0}$ & 0.078 & $\mathbf{2 0}$ & 0.102 \\
\hline $\mathbf{1 1}$ & 0.080 & $\mathbf{2 1}$ & 0.106 \\
\hline $\mathbf{1 2}$ & 0.081 & $\mathbf{2 2}$ & 0.111 \\
\hline $\mathbf{1 3}$ & 0.085 & $\mathbf{2 3}$ & 0.113 \\
\hline $\mathbf{1 4}$ & 0.087 & $\mathbf{2 4}$ & 0.117 \\
\hline
\end{tabular}

$\lambda=0.0261353 t+0.0511038$

Temperature average: $14.5^{\circ} \mathrm{C}$

Thermal conductivity average: $0.089 \mathrm{~W} / \mathrm{m} . \mathrm{K}$

Coefficient of determination: 0.989613

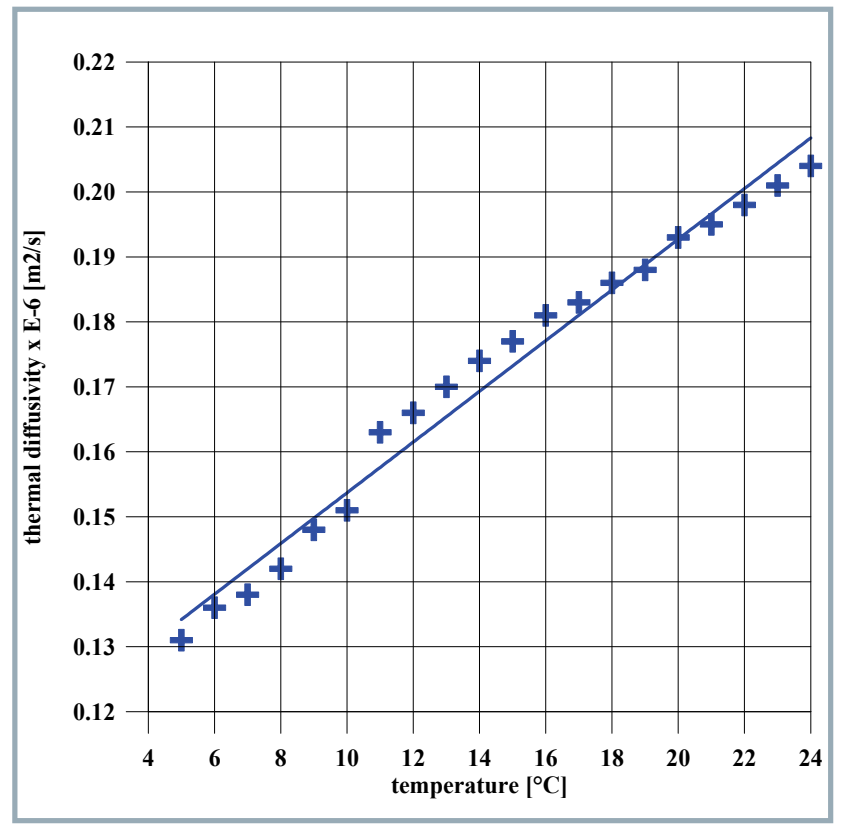

Figure 2 Temperature dependance of thermal difusivity for the soft wheat flour Špeciál 00 Extra in the temperature range $5-24{ }^{\circ} \mathrm{C}$ during the temperature stabilisation

Averages of thermophysical parameters were calculated for data comparison, and results can be summarised in the following numbers: the average of temperature for all measurements is $14.5^{\circ} \mathrm{C}$; the average value of thermal conductivity for the soft wheat flour Špeciál 00 Extra is $0.089 \mathrm{~W} / \mathrm{m} . \mathrm{K}$; the average value of thermal diffusivity is $0.171 .10^{-6} \mathrm{~m}^{2} / \mathrm{s}$; the average value for volume specific heat is $0.5382 \mathrm{~J} / \mathrm{m}^{3} . \mathrm{K}$.

Experimental values obtained for the sample of soft wheat flour Špeciál 00 Extra are in great agreement with values known from literature. In literature, values of thermal conductivity of soft flour are in the range from $0.085 \mathrm{~W} / \mathrm{m} . \mathrm{K}$
Table 2 Experimental values of thermal diffusivity for the soft wheat flour Špeciál 00 Extra in the temperature range $5-24^{\circ} \mathrm{C}$

\begin{tabular}{|l||c|l||c|}
\hline$t$ in ${ }^{\circ} \mathrm{C}$ & $a$ in $\mathrm{m}^{2} / \mathrm{s}$ & $t$ in ${ }^{\circ} \mathrm{C}$ & $a$ in $\mathrm{m}^{2} / \mathrm{s}$ \\
\hline \hline $\mathbf{5}$ & $0.131 .10^{-6}$ & $\mathbf{1 5}$ & $0.177 .10^{-6}$ \\
\hline $\mathbf{6}$ & $0.136 .10^{-6}$ & $\mathbf{1 6}$ & $0.181 .10^{-6}$ \\
\hline $\mathbf{7}$ & $0.138 .10^{-6}$ & $\mathbf{1 7}$ & $0.183 .10^{-6}$ \\
\hline $\mathbf{8}$ & $0.142 .10^{-6}$ & $\mathbf{1 8}$ & $0.186 .10^{-6}$ \\
\hline $\mathbf{9}$ & $0.148 .10^{-6}$ & $\mathbf{1 9}$ & $0.188 .10^{-6}$ \\
\hline $\mathbf{1 0}$ & $0.151 .10^{-6}$ & $\mathbf{2 0}$ & $0.193 .10^{-6}$ \\
\hline $\mathbf{1 1}$ & $0.163 .10^{-6}$ & $\mathbf{2 1}$ & $0.195 .10^{-6}$ \\
\hline $\mathbf{1 2}$ & $0.166 .10^{-6}$ & $\mathbf{2 2}$ & $0.198 .10^{-6}$ \\
\hline $\mathbf{1 3}$ & $0.170 .10^{-6}$ & $\mathbf{2 3}$ & $0.201 .10^{-6}$ \\
\hline $\mathbf{1 4}$ & $0.174 .10^{-6}$ & $\mathbf{2 4}$ & $0.204 .10^{-6}$ \\
\hline
\end{tabular}

$a=0.00390301 t+0.114656$

Temperature average: $14.5^{\circ} \mathrm{C}$

Thermal diffusivity average: $0.171 .10^{-6} \mathrm{~m}^{2} / \mathrm{s}$

Coefficient of determination: 0.978414

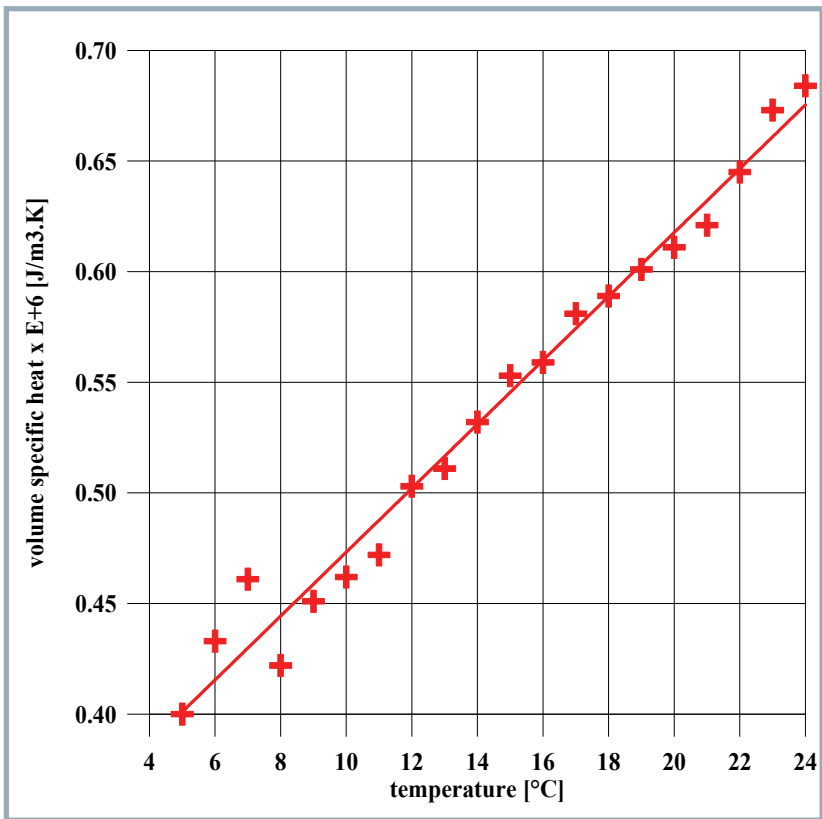

Figure 3 Temperature dependance of volume specific heat for the soft wheat flour Špeciál 00 Extra in the temperature range $5-24{ }^{\circ} \mathrm{C}$ during the temperature stabilisation

to $0.091 \mathrm{~W} / \mathrm{m} . \mathrm{K}$. In case of some differences between values presented in literature, it can be caused by different types of experimental apparatuses, different laboratory settings, or some differences between samples. For soft flour, known values of thermal diffusivity presented in literature are in the interval from $0.168 .10^{-6} \mathrm{~m}^{2} / \mathrm{s}$ to $0.174 .10^{-6} \mathrm{~m}^{2} / \mathrm{s}$. Our average for the thermal diffusivity of soft wheat flour is from the right middle of this interval, so obtained values are in agreement with literature. For the third parameter - volume specific heat, there are not known literature values, because authors present mainly values of thermal conductivity and thermal diffusivity, but if we know the density of measured 
Table 3 Experimental values of volume specific heat for the soft wheat flour Špeciál 00 Extra in the temperature range $5-24^{\circ} \mathrm{C}$

\begin{tabular}{|l||c|l||c|}
\hline$t$ in ${ }^{\circ} \mathrm{C}$ & $c \rho$ in $/ / \mathrm{m}^{3} . \mathrm{K}$ & $t$ in ${ }^{\circ} \mathrm{C}$ & $c \rho$ in $\mathrm{J} / \mathrm{m}^{3} . \mathrm{K}$ \\
\hline \hline $\mathbf{5}$ & $0.400 .10^{6}$ & $\mathbf{1 5}$ & $0.553 .10^{6}$ \\
\hline $\mathbf{6}$ & $0.433 .10^{6}$ & $\mathbf{1 6}$ & $0.559 .10^{6}$ \\
\hline $\mathbf{7}$ & $0.461 .10^{6}$ & $\mathbf{1 7}$ & $0.581 .10^{6}$ \\
\hline $\mathbf{8}$ & $0.422 .10^{6}$ & $\mathbf{1 8}$ & $0.589 .10^{6}$ \\
\hline $\mathbf{9}$ & $0.451 .10^{6}$ & $\mathbf{1 9}$ & $0.601 .10^{6}$ \\
\hline $\mathbf{1 0}$ & $0.462 .10^{6}$ & $\mathbf{2 0}$ & $0.611 .10^{6}$ \\
\hline $\mathbf{1 1}$ & $0.472 .10^{6}$ & $\mathbf{2 1}$ & $0.621 .10^{6}$ \\
\hline $\mathbf{1 2}$ & $0.503 .10^{6}$ & $\mathbf{2 2}$ & $0.645 .10^{6}$ \\
\hline $\mathbf{1 3}$ & $0.511 .10^{6}$ & $\mathbf{2 3}$ & $0.673 .10^{6}$ \\
\hline $\mathbf{1 4}$ & $0.532 .10^{6}$ & $\mathbf{2 4}$ & $0.684 .10^{6}$ \\
\hline \multicolumn{4}{|c|}{$c \rho=0.0144421 t+0.328789$} \\
\end{tabular}

material and basic thermophysical parameters, we can easily calculate volume specific heat. Values of volume specific heat were calculated from density and basic thermophysical parameters according to different authors, and the interval of values for volume specific heat is from $0.510 \mathrm{~J} / \mathrm{m}^{3} . \mathrm{K}$ to $0.542 \mathrm{~J} / \mathrm{m}^{3} . \mathrm{K}$. Our average value is $0.5382 \mathrm{~J} / \mathrm{m}^{3} . \mathrm{K}$, so our result is acceptable for the soft wheat flour.

\section{Conclusion}

For many structural materials, including also bio-based materials, it is important to know the relationships between temperature and thermophysical parameters. For these reasons, in most of experimental observations, there were performed measurements of dependencies for the selected thermophysical parameters (thermal conductivity, thermal diffusivity and volume specific heat) on temperature. In the implementation of experiments, the temperature interval was chosen in view of the measured sample and also with regard to the purpose of usage of results obtained. All relations between thermal parameters and temperature had a linear increasing progress (Figs 1-3), and coefficients of determination had very high values, in the range from 0.978414 to 0.989613 . Experimental values obtained for the sample of soft wheat flour Špeciál 00 Extra were compared with values presented in literature, and we found out that they are in accordance.

\section{Acknowledgement}

This work was co-funded by the European Community under the project no. 26220220180 - Building the Research Centre, AgroBioTech:

\section{References}

BECK, J.V. - ARNOLD, K.J. 2003. Parameter estimation in engineering science. New York : John Wiley, 2003.

BOŽIKOVÁ, M. 2008. Selected thermophysical characteristics of milk and milk products. In Acta Technologica Agriculturae, vol. 11, 2008, no. 1, pp. 15-19.

BOŽIKOVÁ, M. - HLAVÁČ, P. 2010. Selected physical properties of agricultural and food products. Nitra : SUA, 2010. ISBN 978-80-552-0428-4.

CARSLAW, H.S. - JAEGER, J.C. 1959. Conduction of heat in solids. 2nd ed. London : Oxford University Press, 1959.

DANSTER, N. - WOLMARANS, P. - BUITENDAG, C.S. - DE JAGER, A. 2008. Energy and nutrient composition of South African wheat, wheat flour and bread. MRC Cape Town, South Africa, 2008. ISBN 978-1-920014-54-4.

DAVIS, W.R. 1984. Hot-wire method for the measurement of the thermal conductivity of refractory materials. In Compendium of Thermophysical Property Measurement Methods, vol. 1 Survey of Measurement Techniques. New York, London : Plenum Press, 1984.

HEALY, J.J. - DE GROOT, J.J. - KESTIN, J. 1976. The theory of the transient hot-wire method for measuring thermal conductivity. In Physica B+C, vol. 82, 1976, no. 2, pp. 392-408.

KARAWACKI, E. - SULEIMAN, B.M. 2001. Dynamic plane source technique for study of the thermal transport properties of solids. In High Temperatures - High Pressures, 2001, no. 23, pp. 215-223.

KARAWACKI, E. - SULEIMAN, B.M. - UL-HANG, I. - NHI, B.T. 1992. An extension to the dynamic plane source technique for measuring thermal conductivity, thermal diffusivity and specific heat of solids. In Review of Scientific Instruments, 1992, no. 63, pp. 4390-4397.

TAVMAN, I.H. 1996. Effective thermal conductivity of granular porous materials. In International Communications in Heat and Mass Transfer, vol. 23, 1996, no. 2, pp. 169-176.

VOZÁR, L. et al. 2010. Hot wire method [online]. Nitra : UKF. [Retrieved 2010-06-29]. Retrieved from: http://www.tpl.fpv.ukf.sk/ engl_vers/hot_wire.htm

WAKEHAM, W.A. - NAGASHIMA, A. - SENGERS, V.J. 1991. Measurement of the transport properties of fluids. In Experimental Thermodynamics, vol. 3. London : Blackwell Scientific Publications, 1991.

WECHSLER, A.E. 1992. The probe method for measurement of thermal conductivity. In Compendium of Thermophysical Property Measurement Methods, Vol. 2 Recommended Measurement Techniques and Practices. New York, London : Plenum Press, 1992. 